\title{
VIVAT FLORESTA PARQUE SISTEMA ECOLÓGICO - TURISMO SUSTENTÁVEL EM TIJUCAS DO SUL, PR
}

\author{
VIVAT FLORESTA park ecological systems - \\ sustainable tourism in Tijucas do Sul, PR
}

\author{
Benício Melo Filho $^{a}$, Sylvio Péllico Netto ${ }^{\mathrm{b}}$, Izabel Cristina Bruno Bacellar Zaneti ${ }^{\mathrm{c}}$ \\ a Engenheiro Florestal, Dr., Pesquisador associado CDS/UnB. Brasília, DF - Brasil, e-mail: beniciomelo@terra.com.br \\ ${ }^{\mathrm{b}}$ Engenheiro Florestal, Professor titular Dr. da PUCPR, Curitiba, PR - Brasil, e-mail: pellico.sylvio@pucpr.br \\ c Pedagoga, Professora visitante Dra. da CDS/UnB, Professora Visitante. Brasília, DF - Brasil, e-mail: izaneti@terra.com.br
}

\begin{abstract}
Resumo
Este artigo trata da caracterização estrutural do Vivat Floresta Parque Sistema Ecológico- VFPSE, localizado no município de Tijucas do Sul no estado do Paraná, para fins de desenvolvimento do turismo local sustentável. Como base metodológica realizou-se um inventário para observar as variáveis e os indicadores: história cultural, física ambiental, estrutura socioeconômica e político administrativa índice de atração. Em Tijucas do Sul foram identificados: recursos e atrativos turísticos e religiosos; atrações naturais e culturais; trilhas locais e regionais; turismo rural e infra-estrutura turística disponível.
\end{abstract}

Palavras-chave: Turismo; Desenvolvimento local e regional; Estratégias.

\begin{abstract}
This work deals with the structural characterization of a forest denominated VIVAT Floresta Park - Ecological System - VFPSE, located in the municipality of Tijucas do Sul, Parana state, aiming at the developmet of the tourism in a local basis. It is also proposed an strategic evaluation of this potential. As methodological basis, an inventory was carried out to obseve the following variables and indicators: cultural history, environmental physics, social and economical, structure and administrative policies attraction index. In Tijucas do Sul the following touristic resourses and attraction were identified: religious, natural and cultural, rural, local and regional tracks and available infra structure.
\end{abstract}

Keywords: Tourism; Local and regional development; Strategies. 


\section{INTRODUÇÃO}

O VIVAT Floresta Park Sistemas Ecológicos - VFPSE é uma reserva de florestas importante, por estar no domínio da Mata Atlântica, um dos mais ricos biomas ameaçado de extinção no país, com uma área de 5.084 hectares, localizado a uma distância de 50 quilômetros da cidade de Curitiba, nos municípios de São José dos Pinhais, Tijucas do Sul, Agudos do Sul, Estado do Paraná, englobando espécies raras e endêmicas de alto valor florístico e faunístico (Figura 1).

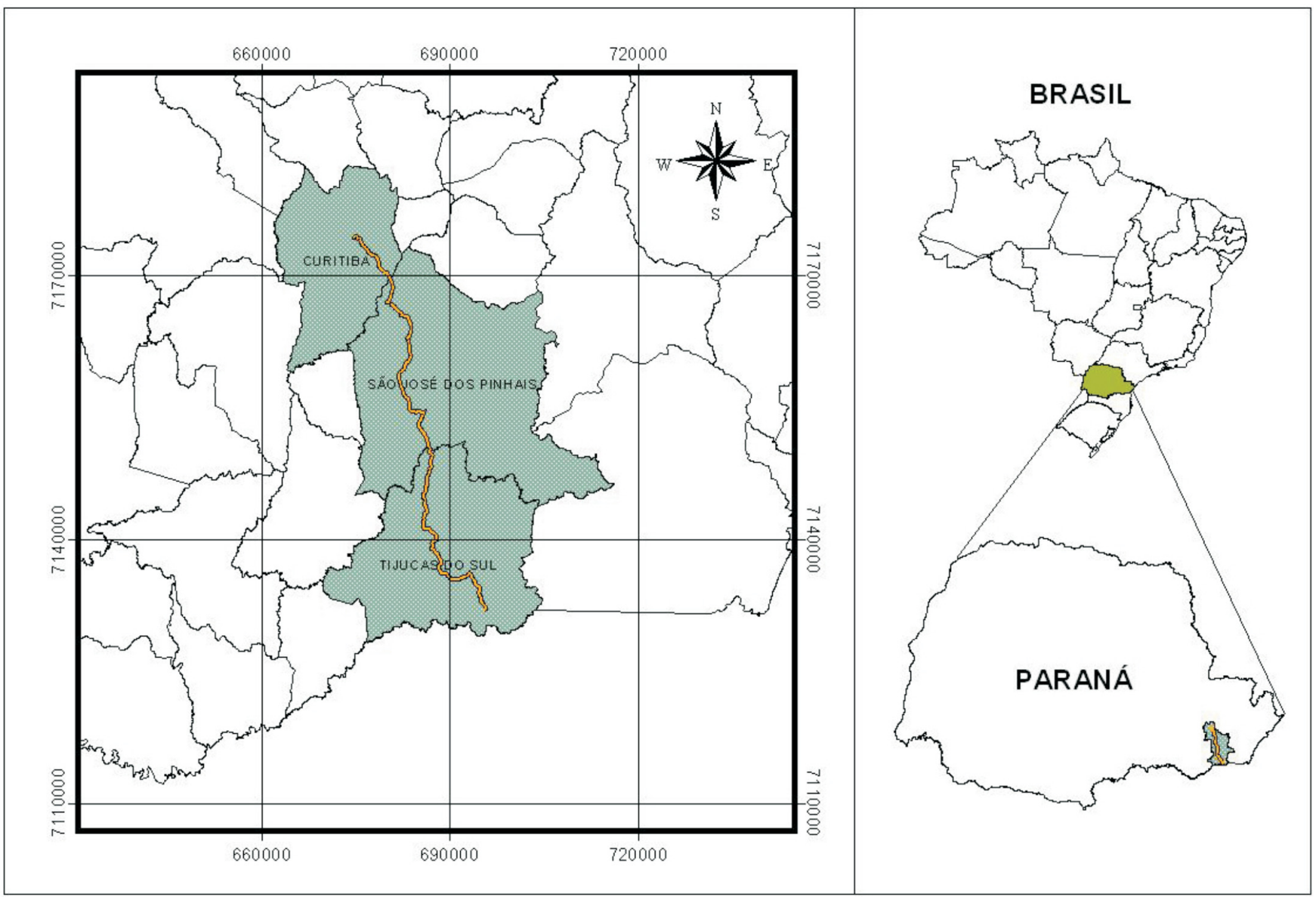

FIGURA 1 - Mapa de ligação da estrada velha de Curitiba a Joinville Figure 1 - Connection map between old road from Curitiba to Joinville

O VFPSE foi criado no ano de 1998, em acordo de cooperação técnica firmado entre a Pontifícia Universidade Católica do Paraná - PUCPR, por meio de sua mantenedora, a Associação Paranaense de Cultura - APC, e a Instituição Filantrópica Sergius Erdelyi - IFSE, entidade de direito privado, sem fins lucrativos, que desenvolve um vultoso trabalho de Ação Social e de Conservação do Meio Ambiente.

A pesquisa teve como temática central o estudo da viabilidade socioeconômica e ambiental, sobretudo de sua utilização como geradora de recursos, para as atividades de uso turístico interno e externo no VFSE, visando implementar um programa turístico fundamentado nos preceitos de desenvolvimento sustentável.

Dentre os vários tipos de turismo, destaca-se o ecoturismo como prioridade deste programa a ser implementado no VFPSE. O turismo é uma atividade que consome o espaço geográfico, exige a construção de infra-estrutura, utiliza-se de recursos naturais e integra a população nativa, porém pode alterar o ambiente. 
É notório explicitar que o desenvolvimento originário do fluxo de turismo pode ser benéfico para a população e para os cofres públicos, como também pode gerar impactos para as comunidades envolvidas. Portanto, é indispensável que esse desenvolvimento seja implementado com planejamento e ênfase na minimização de impactos.

O interesse científico para o turismo está relacionado ao interesse à natureza científica sobre algum aspecto da geomorfologia, geologia, flora, fauna ou em relação aos elementos de vida e atividade humana próprios de alguma região particular (ACERENZA, 2002).

O Centro de Interpretação deve ser pensado de maneira a atender um público de ampla faixa etária, com diferentes graus de instrução e com interesses variados. Tal empreendimento pode ser localizado em áreas particulares, nas quais o proprietário tenha a intenção de desenvolver atividades turísticas (EMBRATUR, 1998).

A área possui endemismos, com destaque para os primatas e aves, que se encontram entre os grupos mais ameaçados de extinção devido aos desmatamentos, integrando as espécies de maior porte, que necessitam de grandes áreas florestadas para sobrevivência (PAIVA, 1999; GASCON; LAURENCE; LOVEJOY, 2001).

A fauna dessa região sofre agressões antrópicas constantes. Os problemas para sua conservação são grandiosos, principalmente decorrentes da fragmentação florestal e da caça. Atualmente, os maiores e mais eficientes refúgios da fauna são as matas de escarpas e grandes altitudes, inacessíveis à ação do homem (PAIVA, 1999).

Apesar do Turismo Ecológico, na atualidade, ser um ramo do turismo que utiliza os recursos naturais e culturais de um determinado lugar, ele contribui para conservá-los, buscando desenvolver o respeito pela natureza por meio do contato com o ambiente natural e promovendo o bem-estar das populações locais envolvidas.

Rabahy e Abrahão (2003), tratando do potencial e das tendências do turismo em todo o mundo afirma que esta é a principal atividade econômica e a que mais cresce, empregando mais gente no mundo do que a totalidade da população brasileira; na atualidade, a maioria das pessoas que viaja a passeio é de ecoturistas; é um tipo de turismo em rápida expansão, apresentando, nos últimos 10 anos, taxa de crescimento de $7 \%$ ao ano.

Os pressupostos para um projeto dinâmico do VFPSE são de transformação ambiental e socioeconômica, fundamentados nos preceitos de auto-sustentabilidade preconizados na Agenda 21 Brasileira (2002) e Agenda 21 Global, que visam implementar no seu ambiente o uso da propriedade, nos moldes do manejo florestal fundamentado em múltiplas atividades ambientais e culturais integradas ao turismo. A promoção e difusão de pesquisa agroflorestal, edáfica e faunística estão relacionadas ao desenvolvimento, à restauração e ao uso sustentável das florestas.

\section{MATERIAIS E MÉTODOS}

A relação de material utilizado na pesquisa foi disponibilizada para identificar, registrar e caracterizar os locais, produtos turísticos, setores integrados ao turismo, infra-estruturas turísticas, equipamentos turísticos, atrações naturais, históricas, culturais e científicas.

Para as visitações in loco, foram usados um GPS, mapas municipais, diário de campo e um guia, funcionário do VFPSE que acompanhou nos locais visitados (nativo da região, cantador, dançarino de músicas folclóricas e mateiro), nas comunidades e no município.

O reconhecimento das trilhas foi efetuado com um jipe e por caminhadas em diversos pontos que mostravam potenciais turísticos. Para a pesquisa de campo foram disponibilizados, também, um gravador, fitas magnéticas, máquina fotográfica digital e máquina fotográfica não-digital; mapas da COMEC/IPARDES-PR (2002). A técnica utilizada para reconhecimento dos caminhos e trilhas foi a de percorrer os locais e efetuar observações sobre recursos naturais da fauna e da flora como também realização de entrevistas e visitas às comunidades, para se conhecer seus hábitos culturais. 


\section{Elaboração dos mapas}

Inicialmente, para a elaboração dos mapas de roteiros turísticos do VIVAT Floresta Park e do município de Tijucas do Sul - PR, foram realizados levantamentos de informações cartográficas secundárias em diversas instituições públicas e empresas privadas, objetivando o agrupamento de informações cartográficas, imagens de satélite, fotografias aéreas e materiais bibliográficos relacionados à área de estudo e o seu entorno.

Como resultado do levantamento dos dados secundários foram identificados os seguintes materiais:

- mapa elaborado pela Secretaria de Estado do Planejamento e Coordenação Geral do Governo do Estado do Paraná, por meio da Coordenação da Região Metropolitana de Curitiba (COMEC), para o qual foram utilizadas imagens de satélite LANDSAT 7 TM+ de 26/09/1999;

- mapa desenvolvido pela empresa de consultoria Silviconsult Ltda. para PANAGRO Empreendimentos Florestais Ltda. na escala de 1: 30.000, elaborado em 10 de junho de 2000, para o qual se utilizou imagem do satélite LANDSAT 7 TM+, órbita/ponto 220/ 078 de 26/09/1999 em composição colorida 5R, 4G e 3B mais pancromática apoiados por levantamentos de campo com o uso de GPS diferencial topográfico;

- imagem LANDSAT 7 TM+, órbita ponto 220/078 de 02/09/2002 em formato bruto;

- carta topográfica elaborada pelo Instituto Brasileiro de Geografia e Estatística (IBGE) em convênio com a Companhia Paranaense de Energia (COPEL), do município de Tijucas do Sul, elaboradas durante 1980 a 1991 e impressos em 1992, na escala de 1:50.000, com curvas de 20 metros de eqüidistância, folha SG 22-X-D-IV-4 MI 2857-4;

- arquivos vetoriais da altimetria do VFPSE;

- arquivos de levantamentos internos de trilhas/caminhos e outras feições do VIVAT Floresta.

Após o levantamento destas informações, deu-se inicio ao levantamento de campo realizado durante o período de julho de 2004 a agosto de 2005. Utilizou-se durante o trabalho de campo o GPS de navegação de marca GARMIN, modelo 12, com o qual foram registrados waypoints (registros de coordenadas de pontos) e tracks (registro de coordenadas de caminhos). Optou-se pela utilização de GPS de navegação pelo baixo custo.

Sequencialmente, os waypoints e tracks foram descarregados em micro computadores por meio da utilização do software GPS Trace $M a k e r^{\mathbb{R}}$ e, posteriormente, convertidos em arquivo ASCII, os quais foram importados pelo software ArcGis 8 e plotados sobre as feições levantadas durante os levantamentos de campo e das fontes secundárias de informações.

Para a caracterização geral da área de estudo, utilizou-se uma imagem do satélite LANDSAT 7 ETM+, da órbita/ponto 220/78, adquirida em 02 de setembro de 2002, com as quais se realizou a fusão das bandas 5, 4 e 3 (resolução espacial de 30 metros) com a banda pancromática (resolução espacial de 15 metros), obtendo-se, dessa forma, um produto com uma resolução espacial de 15 metros. A seguir a imagem sofreu uma correção radiométrica, de forma sistemática e associada a um sistema de projeção cartográfica, o sistema Universal Transverse Mercator (UTM) e o datum horizontal de referência SAD 69.

A imagem LANDSAT trabalhada foi, no entanto, incorporada ao trabalho para dar uma visão geral da área de estudo e de sua inserção na região em que se localiza. Finalmente, os arquivos vetoriais georeferenciados foram convertidos para arquivos matriciais o que possibilitou trabalhar com o software Corel Draw 10 para a inclusão da simbologia e informações dos pontos turísticos, permitindo, assim, uma melhor formação do mapa turístico da região (Figura 2). 


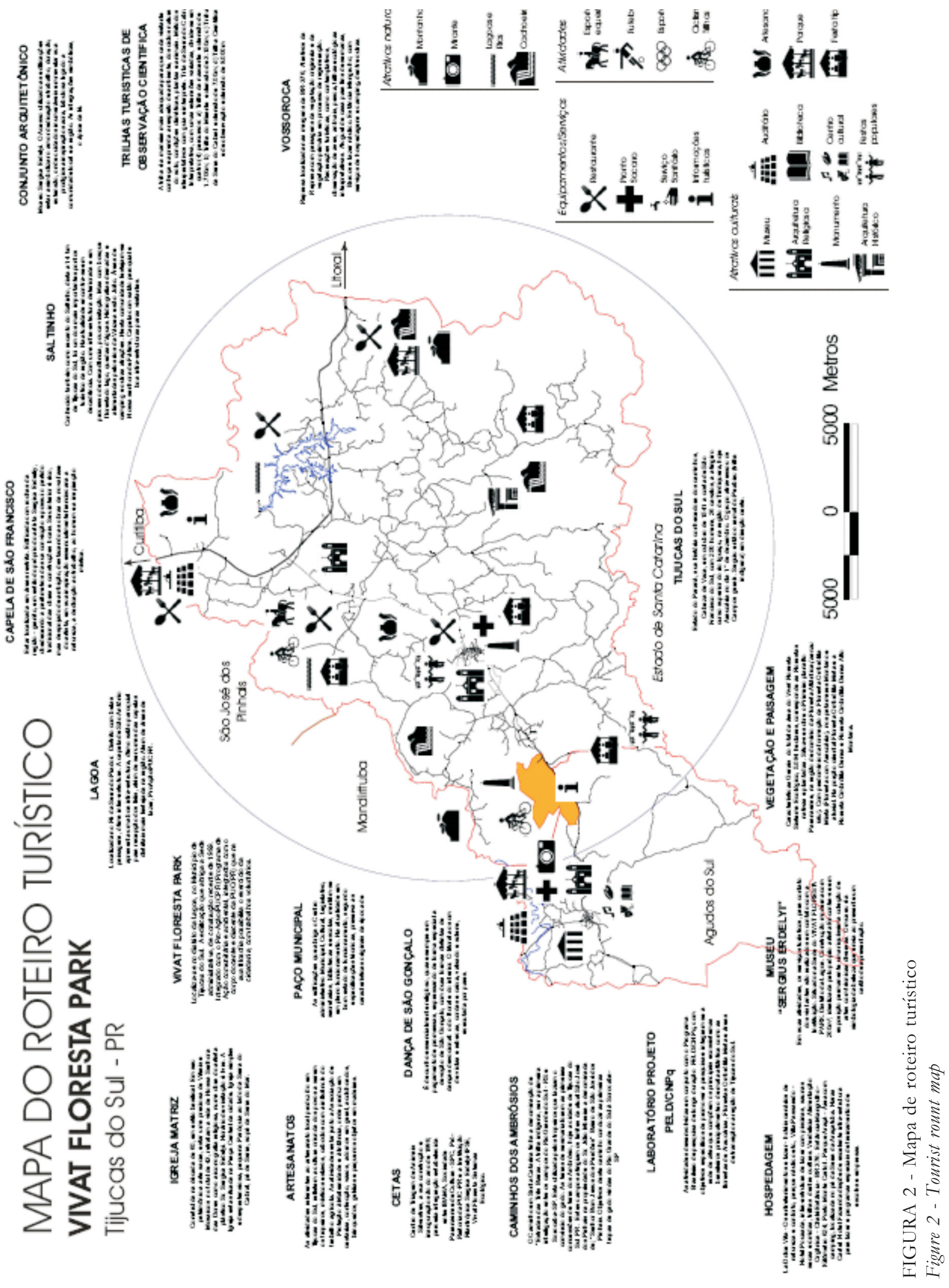




\section{RESULTADOS E DISCUSSÃO}

As áreas de interesse ecoturístico do Estado do Paraná são três: as Cataratas do Iguaçu; os Campos Gerais, planalto com Florestas de Araucárias e o litoral, com duas grandes baías e a Mata Atlântica.

A implementação do Parque, na Região Metropolitana de Curitiba, pressupõe a existência de relações socioeconômicas, o surgimento de novos empreendimentos, a construção de um novo papel social, a criação de campos radiadores de emprego, aproveitamento econômico dos recursos naturais existentes e ampliação de alternativas de hábitos das comunidades para cultuar os costumes.

\section{Mapa das trilhas turísticas}

Neste trabalho foi gerado um mapa temático turístico e das trilhas existentes, destacandose a ligação de Curitiba a Tijucas do Sul pela antiga estrada velha Joinville - Curitiba. Também estão destacados os Mapas de Roteiro Turístico do VFPSE e do município, como os cursos de água.

Foi realizado um caminhamento por GPS, ligando os primeiros caminhos do desenvolvimento ao complexo turístico do VFPSE, como requisito cultural dos "Primeiros caminhos do desenvolvimento", unindo a cidade de Curitiba ao VFPSE, como mostra o Mapa, para seguir os caminhos do Brasil. O roteiro iniciou-se na cidade de Curitiba, seguindo até São José dos Pinhais pela estrada velha JoinvileCuritiba, Baixada do rio Miringuava, Bom Jesus dos Perdões, Campo Largo das Roseiras, monumento religioso Pedro Moura, Tabatinga, Gruta do Monge, Tijucas do Sul, Vivat Floresta, Caminho dos Ambrósios, Trilha pré-Cabralina (Caminho dos Tropeiros), Casa do pedágio, Serrinha, rio Piraí Mirim e Reflorestamento da COMFLORESTA, ligando o complexo turístico da Estrada Bonita e Joinvile. Essa caminhada é de 55 quilômetros, estando 42 quilômetros no município de Tijucas do Sul, área lindeira ao complexo do VFSE.

A Tabela 1 indica o grau de valoração dos recursos e atrativos turísticos ofertados pelo VFPSE.

TABELA 1 - Atrativos prioritários do VFSE

Table 1 - Priority attraction of the VFSE

\begin{tabular}{|c|c|c|c|c|}
\hline \multirow[t]{2}{*}{ Recursos (R) e, ou, Atrativo (A) } & \multicolumn{3}{|c|}{ Grau de valoração } & \multirow{2}{*}{$\begin{array}{c}\text { Índice de } \\
\text { qualidade do visual }\end{array}$} \\
\hline & Integridade & Memorização & Unidade & \\
\hline 1. VFSE - Museu & 3 & 3 & 3 & 3 \\
\hline 2. CETAS & 2 & 2 & 2 & 2 \\
\hline 3. Programa de estudos turísticos & 3 & 2 & 2 & 2,5 \\
\hline 4. Caminhadas dirigidas com interpretação & 1 & 0 & 1 & 1 \\
\hline 5. Trilhas observação de animais, etc. & 1 & 0 & 3 & 2 \\
\hline 6. Manejo Eco-Silvilcultural & 2 & 1 & 1 & 2 \\
\hline 7. Observatório Serra do Cabral & 1 & 0 & 1 & 1 \\
\hline 8. Contemplação-ecologia da paisagem & 1 & 2 & 1 & 2 \\
\hline 9. Arboreto e ervas medicinais & 1 & 0 & 1 & 1 \\
\hline 10. Capela de São Francisco & 1 & 1 & 2 & 2 \\
\hline 11. Obeliscos e obras de artes & 2 & 3 & 1 & 3 \\
\hline 12. Ermida & 1 & 1 & 1 & 1,5 \\
\hline 13. Viveiros e apicultura & 0 & 0 & 1 & 0 \\
\hline 14. Quadras-poliesportivas e auditório & 0 & 0 & 1 & 0 \\
\hline 15. Fontes d’águas e santuários ecológicos & 1 & 0 & 1 & 1 \\
\hline 16. Lagos & 0 & 1 & 1 & 1 \\
\hline
\end{tabular}

Fonte: Melo Filho (2005). 


\section{Entrevistados residentes na região}

Tijucas do Sul: Foram entrevistadas 72 pessoas, com renda econômica e cultural diferentes. Na primeira etapa do questionário foram entrevistadas 28 pessoas, em caráter experimental; na segunda etapa, já com o objetivo definitivo da pesquisa, foram entrevistadas 44 pessoas com as mesmas características socioeconômicas e culturais, nos distritos e na sede municipal.

Locais identificados: foram registrados 14 pontos turísticos na área do VFSE de 38 identificados no município de Tijucas do Sul, conforme apresentado na Tabela 2. Foram contabilizados 16 recursos turísticos e 20 atrativos turísticos prioritários.

TABELA 2- Recursos e atrativos turísticos - Tijucas do Sul e entorno

Table 2 - Resources and touristic attraction - Tijucas do Sul and neighboring

\begin{tabular}{|c|c|c|c|}
\hline Empreendimento & Local e Distrito & Atividades & Infra-estrutura \\
\hline VFSE & Lagoa & $\begin{array}{l}\text { Museu, trilhas, turismo } \\
\text { cientifico, cultural e } \\
\text { lúdico etc. }\end{array}$ & $\begin{array}{l}\text { Sede Administrativa, } \\
\text { Alojamento Universitário, } \\
\text { quadra poli-esportivas } \\
\text { e Atendimento médico. }\end{array}$ \\
\hline $\begin{array}{l}\text { Caminho dos } \\
\text { Ambrósios }\end{array}$ & Tijucas a Joinville-SC & $\begin{array}{l}\text { Patrimônio Histórico, } \\
\text { Natural e Arqueológico, } \\
\text { Rios, paisagens nativas }\end{array}$ & $\begin{array}{l}\text { Trilhas, pré-histórica em } \\
\text { processo de implantação, } \\
\text { acampamento. }\end{array}$ \\
\hline La Dolce Vita & Rio do Una & $\begin{array}{l}\text { Lazer \& Eventos, Barcos, } \\
\text { Tirolesa, Trilhas, etc. }\end{array}$ & $\begin{array}{l}\text { Lazer \& eventos, Barcos, } \\
\text { piscina, tirolesa, e esportes. }\end{array}$ \\
\hline Vila Passaredo & Estrada do Rio Abaixo & $\begin{array}{l}\text { Lazer \& Eventos ginásio } \\
\text { de escalada e tirolesa, } \\
\text { auditório e trilhas. }\end{array}$ & $\begin{array}{l}\text { Hotel de Lazer \& eventos, } \\
\text { Barcos, piscina e escaladas. }\end{array}$ \\
\hline Haras Cartel & Campo Alto & $\begin{array}{l}\text { Passeio de cavalos, } \\
\text { hotel-fazenda. }\end{array}$ & $\begin{array}{l}\text { Lazer \& Cavalgadas e } \\
\text { Natureza, trilhas, etc. }\end{array}$ \\
\hline Estância Mangrulho & Vossoroca-BR 376 & $\begin{array}{l}\text { Passeios de Barco e. } \\
\text { de Jetski }\end{array}$ & $\begin{array}{l}\text { Pescarias, chalés, Pousadas, } \\
\text { chalés, pescas, passeio de } \\
\text { barcos, Jetski etc. }\end{array}$ \\
\hline Parque Araçá & Serra da Araçatuba & $\begin{array}{l}\text { Trilhas e chalés e piscinas } \\
\text { naturais }\end{array}$ & $\begin{array}{l}\text { Chalés, pousadas e trilhas, } \\
\text { piscinas, montanhas, camping }\end{array}$ \\
\hline Estância Ribeirão Grande & $\begin{array}{l}\text { Estrada Municipal } \\
\text { Agudos do Sul }\end{array}$ & $\begin{array}{l}\text { Pesque-pague e } \\
\text { outras atrações }\end{array}$ & Chalés, restaurantes etc. \\
\hline Verdelicia & BR 376 & $\begin{array}{l}\text { Agricultura orgânica e } \\
\text { alimentação natural }\end{array}$ & $\begin{array}{l}\text { Restaurantes, Chalés, Atividades } \\
\text { lúdicas,e Restaurantes e Trilhas }\end{array}$ \\
\hline Carril Campo Alto & BR 376 & Curso de laticínios etc. & Cursos de laticínios, chalés e hotel \\
\hline Estância Terras Altas & BR 376 & Ponto fraco em organização & Hotel, restaurantes, pesque-pague. \\
\hline Recanto Saltinho & Saltinho & $\begin{array}{l}\text { Ponto fraco - processo } \\
\text { de decadência. }\end{array}$ & $\begin{array}{l}\text { Camping, restaurante, cachoeira, } \\
\text { parque (Fraco). }\end{array}$ \\
\hline Chácara São José & BR 376 & Pesque-pague, cachoeiras etc. & $\begin{array}{l}\text { Pesque-pague, restaurante, passeios } \\
\text { lúdicos. }\end{array}$ \\
\hline Tijucas do Sul & Sede Municipal e Distritos & $\begin{array}{l}\text { Obras sacras, Igreja Nossa } \\
\text { Senhora das Dores, festas } \\
\text { populares e distritais etc. }\end{array}$ & $\begin{array}{l}\text { Restaurantes, obras de arte sacras, } \\
\text { festas religiosas, artesanatos, } \\
\text { museu, Ambrósios, história. }\end{array}$ \\
\hline
\end{tabular}

Fonte: Melo Filho (2005).

Rev. Acad., Ciênc. Agrár. Ambient., Curitiba, v. 6, n. 2, p. 281-292, abr./jun. 2008 
No mapa roteiros turísticos (Figura 3), foram incluídos os equipamentos e atrativos urbanos, equipamentos e atrativos rurais, atrativos naturais e atrativos históricos culturais, manifestações populares, equipamentos e serviços turísticos, infra-estrutura existente e roteiro turístico.

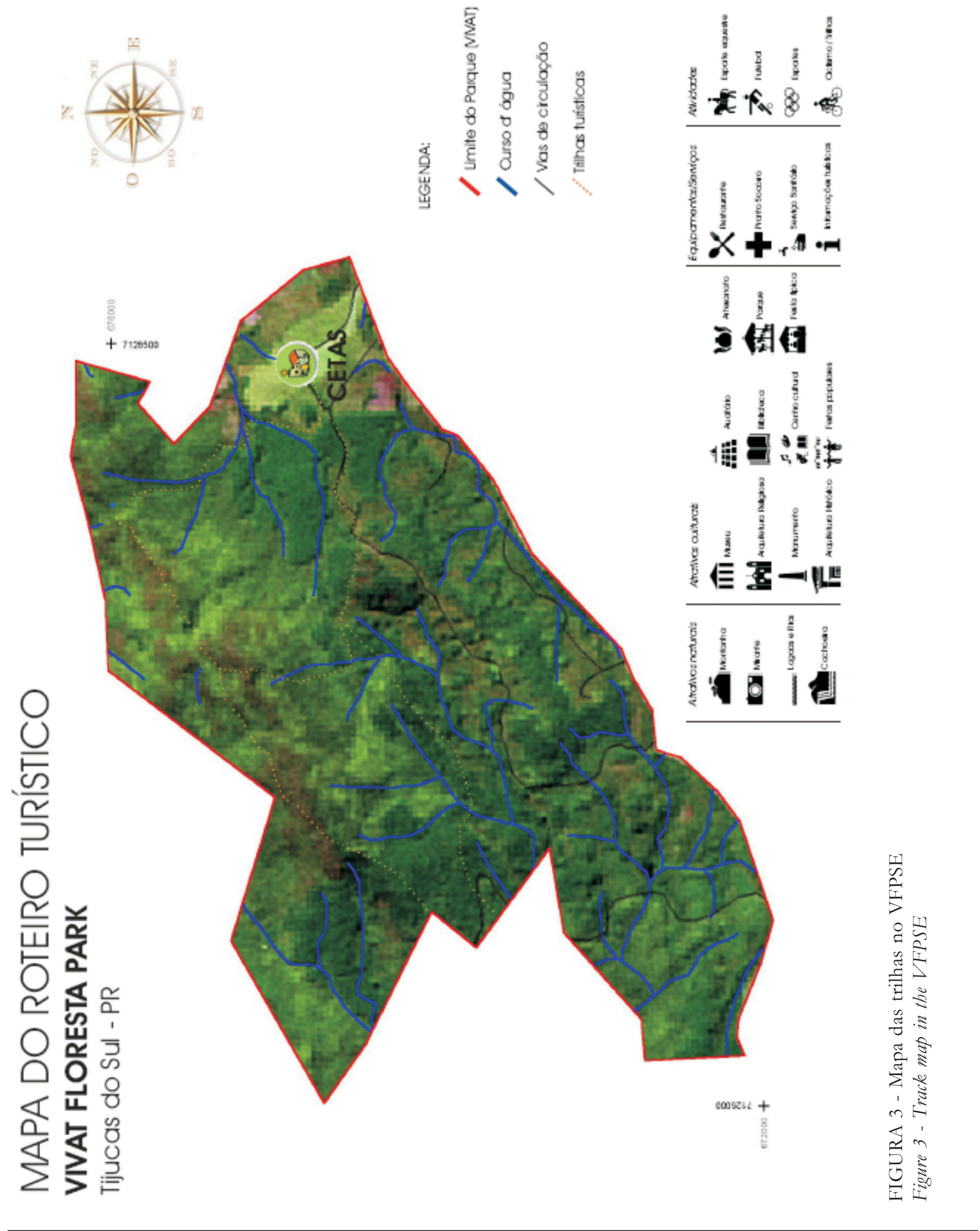

Rev. Acad., Ciênc. Agrár. Ambient., Curitiba, v. 6, n. 2, p. 281-292, abr./jun. 2008 
O museu Sergius Erdelyi surgiu no início da década de 1990 no Recanto Saltinho, em Tijucas do Sul. O artista Sergius Erdelyi, austríaco de múltiplos talentos, residente há 30 anos em Tijucas do Sul, há bastante tempo planeja reunir parte de seu grande acervo de obras de arte (vitrais, esculturas e pinturas) em um museu acessível ao público.

O primeiro museu construído em madeira e cobertura de telhas fibro-cimento, pintadas com motivos ornamentais idealizados pelo próprio artista, foi inaugurado em 24 de fevereiro de 1999. Esse museu funcionou até 2001, período que recebeu a visita, com registro formal, de 8.592 visitantes no total, para os anos de 1989,1990 e 1991. Um novo museu foi construído na área da Associação Paranaense de Cultura, mantenedora da PUCPR, onde também abriga o ProAção, em Tijucas do Sul, em estreita colaboração com o professor Clemente Ivo Juliatto, Reitor da PUCPR, quando escolheu-se um projeto do próprio artista. A construção foi iniciada em março de 2003 e concluída no ano seguinte. Localiza-se na Estrada São Marcelino Champagnat, s/n, bairro Lagoa, Tijucas do Sul, PR.

Foi realizada uma análise com base em elementos estruturais, conjunturais e qualitativos do CETAS, como infra-estrutura, Livro de Registro da Triagem de Animais, constando nome, procedência, data de entrada e saída, registro e destinos dos animais recebidos. Esse Centro é dirigido pela Diretoria de Órgãos Suplementares da Associação Paranaense de Cultura - APC, integrado em parceria estabelecida com o IBAMA, APC e a Instituição Filantrópica Sergius Erdelyi - IFSE.

As atividades realizadas no CETAS objetivam a recuperação, tratamento, triagem e proteção de animais das classes: Mamária, Reptalia e Aves da Fauna Brasileira.

Os animais, depois do registro e catalogação, recebem tratamento adequado e cuidados veterinários até a sua reabilitação e destinação ao ambiente adequado, natural ou ambiente controlado (criadouros, zoológicos, entre outros).

Segundo informações coletadas in loco, o CETAS/PUCPR/ENTREVISTAS (2004) oferece uma vultosa colaboração para práticas acadêmicas de caráter técnico-científico para as aulas ministradas nos cursos de Medicina Veterinária, Zootecnia, Biologia e pós-graduação em diversas áreas do conhecimento integrado à conservação; oferece ainda treinamento para profissionais e estudantes de outros Centros de Ensino, pesquisa e de instituições universitárias nacionais e internacionais, obedecendo a parâmetros de administração e rigor técnico.

Em Tijucas do Sul há um museu que está inserido no complexo do VFSE. Esse museu recebe visitação, desde 1989, de pessoas de todo o Estado do Paraná. A pesquisa de campo mostrou que 24 localidades registraram até nove visitações e o total de visitantes foi de 2.579, revelando, desse modo, o potencial desse atrativo. Por esse motivo, foi realizado um inventário das obras do MUSEU SERGIUS ERDELYI.

O processo de caracterização utilizado para o levantamento desses recursos e atrativos culturais foi sistemático, passando nas comunidades distritais por meio de visitas a cada um dos locais e avaliando, observando, realizando anotações com os entrevistados, fotografando e utilizando o GPS (sistema de posicionamento global, do inglês global position system) para melhor localizar esses empreendimentos, as localidades e a infra-estrutura existente.

A atribuição de valor e apreciação das características dos atrativos culturais são extremamente subjetivos, estes já existem e formam parte da história local, são inerentes as tradições e costumes das populações, integrados ou não ao turismo.

Os critérios de hierarquização fornecem subsídios para a diferenciação objetiva das características e os graus de hierarquia e importância entre os atrativos e permitem uma avaliação da intensidade da atratividade, estabelecendo uma ordem para priorizar o desenvolvimento do turismo, conforme metodologia proposta por OMT/CICATUR (1999), citado por Silveira (2003). A Tabela 2 caracteriza os empreendimentos e recursos turísticos locais e dos distritos, as atividades e a infra-estrutura.

A Tabela 2 apresentada é um indicador dos principais itens do trabalho da pesquisa de planejamento e gestão do turismo regional e local (pólo turístico), inventariado os recursos disponíveis na região, como um dos principais indicativos descritos no Mapa turístico. Deste modo, as informações específicas coletadas serão lançadas e divulgadas diretamente no programa de visitação do roteiro turístico do VIV AT Floresta como do Município de Tijucas do Sul. Todas as informações de interesse público e ao turismo serão tratadas e publicadas em folhetos e informativos disponíveis ao turista.

Rev. Acad., Ciênc. Agrár. Ambient., Curitiba, v. 6, n. 2, p. 281-292, abr./jun. 2008 


\section{Trilhas turísticas mapeadas}

As quatro trilhas detectadas na área do VFPSE, de acordo com o Mapa Temático, foram nominadas e determinadas de acordo com sua localização, características, belezas cênicas e naturais encontradas, como também acessibilidade, freqüência de visitações dos habitantes do lugar ao morro do pico, na Serra do Cabral. Esse lugar apresenta uma panorâmica de toda a região, com paisagem espetacular da Serra do Mar e de municípios vizinhos.

Trilha A - Trilha da Serra do Cabral (Trilha Grande) com uma extensão de 7.800 metros, tempo da caminhada de $4 \mathrm{~h}$ a $4 \mathrm{~h} 30 \mathrm{~min}$. Apresenta bastante obstáculos.

Trilha B - Trilha da Santa Clara (Trilha Média) com extensão de 6.800 metros. Tempo de duração da caminhada de $3 \mathrm{~h}$ a $3 \mathrm{~h} 30 \mathrm{~min}$.

Trilha C - Trilha das Gralhas (Trilha Pequena) com extensão de 3.200 metros. Tempo de duração da caminhada de $2 \mathrm{~h}$ a $2 \mathrm{~h} 30 \mathrm{~min}$.

Trilha D - Trilha da Contemplação da Natureza (Trilha das Nascentes) com extensão de 1.700 metros. Tempo de duração da caminhada de 1 h30min a $2 \mathrm{~h}$.

\section{O Caminho dos Ambrósios}

Dentre os nove roteiros turísticos propostos pelo Estado do Paraná para integrar um megaprojeto turístico no Estado, incluiu-se o roteiro dos Ambrósios para inseri-lo no turismo paranaense, pelas suas potencialidades, especialmente pela presença do VFPSE, integração e participação deste no processo de gestão dos circuitos turísticos. Destaca-se por sua relevância histórica e pelos diversos caminhos abertos pelos indígenas, como o caminho do Peabiru, que do litoral paulista chegava até a Bolívia e Peru, e diversas trilhas que ligavam o litoral aos campos do "além serra".

\section{CONCLUSÃO}

As ofertas brasileiras dos produtos turísticos respondem as estratégias prioritárias que integram os negócios e os investimentos de grandes empresas do setor no Brasil;

As maiores ofertas de atrações turísticas encontram-se na região Nordeste, grande pólo de atrações, procurado pelos turistas estrangeiros, que em 2005 recebeu 5,8 milhões de visitantes. O Brasil tende a responder por uma parcela cada vez maior na indústria do turismo, gerando cerca de R \$ 94 bilhões para a economia nacional. Pode crescer para $\mathrm{R} \$ 222$ bilhões até 2010 , com $4,2 \%$ do crescimento real na próxima década, representando $3,8 \%$ do PIB. Os fatos se comprovam neste momento em que o Brasil oferece um turismo de qualidade e gerador de divisas. Tal realidade justifica e confirma a hipótese postulada de produtos, caracterizada pelo potencial turístico da região estudada;

A oferta de serviços no turismo aumenta na caracterização das áreas de atuação, ainda não orientada para o suprimento dos mercados externos e internos. Portanto, esses resultados significam que o crescimento dinâmico nas áreas de atuação necessita de orientação adequada dos agentes diretos e indiretos dos serviços turísticos;

A demanda e oferta dos produtos turísticos nos pólos de atração requerem grandes investimentos. Essas características regem o mercado dos produtos naturais, culturais e da paisagem e sugerem que o setor deve incrementar a modernização dos sistemas turísticos básicos e a adoção de novas técnicas e aprendizagem para um atendimento excelente do mercado;

As potencialidades turísticas locais e regionais apresentam dados favoráveis, como é o caso de Tijucas do Sul - PR, que se enquadra no espaço rural sul brasileiro, onde há uma fisionomia da paisagem propriamente associada ao caráter sociocultural;

Os resultados sugerem algumas mudanças nas políticas públicas e econômicas. Um aumento nos investimentos empresariais ao setor, com objetivos de aumentar o potencial de crescimento da 
economia local e regional é fundamental. Isto se justifica porque na análise dos diagnósticos socioeconômico, características da paisagem local e do potencial turístico são comprovadamente relevantes para consolidar os produtos turísticos e agregar valores aos produtos locais, no sentido de promover o desenvolvimento do turismo regional;

Tudo isso leva à conclusão de que a participação brasileira na identificação das localidades onde a prática do ecoturismo é crescente e a realização de inventários das características, das potencialidades, da infra-estrutura de apoio disponível, das instituições para desenvolver, identificar e avaliar os pólos de desenvolvimento do ecoturismo aumentam a procura por esses serviços no mercado interno;

Cabe aos órgãos oficiais reguladores a implantação de medidas que visem incentivar os interessados no planejamento das atividades ecoturísticas, com subsídios que poderão auxiliar o planejamento dessas atividades em seu município, propriedades ou empreendimento, ferramentas para a escolha de parcerias públicas e privadas, a implantação de projetos de manejo ecoturístico, a evitar atraso do desenvolvimento socioeconômico das regiões receptoras e evitando perdas de divisas do país;

O fomento e os incentivos econômicos, bem como as capacitações, são necessárias ao desenvolvimento sustentável e à sustentação do desenvolvimento econômico, com a geração de lucros e expansão de mercado;

A manutenção desses processos de desenvolvimento como mecanismo apropriado ao quadro brasileiro atual ocorre concomitantemente em escala regional: o econômico, o ambiental e comunitário. O que se pode é aproveitar as potencialidades naturais de cada região e implementar políticas públicas que visem o desenvolvimento do setor turístico integrado aos recursos naturais e regionais na consecução dessas atividades;

Deve-se destacar que ações estratégicas para encadeamento das atividades ecoturísticas como: regulamentação, interação institucional, capacitação de recursos humanos, qualidade do produto, gestão, adequação de infra-estrutura e participação da comunidade, agregação de valores aos produtos, modernização de infra-estrutura são políticas a ser implementadas e desafios a serem solucionados pelo setor.

\section{AGRADECIMENTOS}

Agradecemos ao Professor Doutor Sylvio Péllico Netto pela dedicação e estímulo, pela compreensão e pela amizade sempre presentes.

Ao Sr. Sérgio Erdelyi pelo apoio e informações e a toda equipe do VIVAT PARK que forneceram toda a estratégia e logística das atividades de campo.

\section{REFERÊNCIAS}

ACERENZA, M. Á. Administração do turismo: conceituação e organização. Bauru: EDUSC, 2002. ACERENZA, M. Administração do turismo: conceituação e organização. Bauru: EDUSC, 2002. AGENDA 21 BRASILEIRA - Ações Prioritárias/comissão de políticas de desenvolvimento sustentável e da agenda 21 Nacional. Decreto presidencial 2.1656, Publicado no DOU de 27.2.97. MMA/PNUD V.I, II. Brasília: [s.n.], 2002.

COMEC $\backslash$ IPARDES- Instituto paranaense de desenvolvimento econômico e social. Cadernos Estatísticos Municipais - Guaratuba, São José dos Pinhais e Tijucas do Sul. Curitiba: IPARDES, 2002.

EMBRATUR/IEB. Pólos de desenvolvimento de ecoturismo no Brasil nas regiões Sul e Centro-Oeste. Brasília: EMBRATUR, 1998. 
ENTREVISTA concedida pelo Sr. Sergius Erdelyi. Sede do Museu Localidade Lagoa. Município de Tijucas do Sul. 22 de novembro de 2004.

GASCON, C.; LAURENCE, W. F; LOVEJOY, T. E. Fragmentação florestal e biodiversidade na Amazônia central. In: GARAY, I.; DIAS, B. Conservação da biodiversidade em ecossistemas tropicais: avanços conceituais e revisão de novas metodologias de avaliação e monitoramento. Petrópolis, RJ: Vozes, 2001. p. 112-127.

OMT/CICATUR. Changes in leisure time: the impact in tourism. Madrid: Word Tourism, 1999. NOTÍCIAS DO TURISMO. Brasília: [s.n.], 2006. Disponível em: <http. \\www.turismo.gov.br $\backslash$ br $\backslash$ brconteudo. Ver.asp? Conteudopd=3006\&id=188>. Acesso em: 17 maio 2006.

PAIVA, M. P. Conservação da fauna brasileira. Rio de Janeiro: Interciência, 1999.

RABAHY, W. A. Turismo e desenvolvimento: estudos econômicos e estatísticos no planejamento. São Paulo: Manole, 2003.

SILVEIRA, M. A. T. Turismo, políticas de ordenamento territorial e desenvolvimento: um foco no Estado do Paraná no contexto regional. 2003. 277 f. Tese (Doutorado em Geografia) Faculdade de Filosofia, Letras e Ciências Humanas, Universidade de São Paulo, São Paulo, 2003.

Recebido: 24/03/2007

Received: 03/24/2007

Aprovado: $15 / 01 / 2008$ Approved: 01/15/2008 